\title{
A Biopsychosocial Profile of Adult Canadians with and without Chronic Back Disorders: A Population-Based Analysis of the 2009-2010 Canadian Community Health Surveys
}

\author{
Brenna Bath, ${ }^{1,2}$ Catherine Trask, ${ }^{2}$ Jesse McCrosky, $^{3}$ and Josh Lawson ${ }^{2}$ \\ ${ }^{1}$ School of Physical Therapy, College of Medicine, University of Saskatchewan, 1121 College Drive, \\ Saskatoon, SK, Canada S7N 0W3 \\ ${ }^{2}$ Centre for Health and Safety in Agriculture, College of Medicine, University of Saskatchewan, 103 Hospital Drive, \\ Saskatoon, SK, Canada S7N 0W8 \\ ${ }^{3}$ Department of Community Health and Epidemiology, College of Medicine, University of Saskatchewan, \\ 103 Hospital Drive, Saskatoon, SK, Canada S7N 0W8 \\ Correspondence should be addressed to Brenna Bath; blm129@mail.usask.ca
}

Received 13 February 2014; Revised 21 April 2014; Accepted 6 May 2014; Published 27 May 2014

Academic Editor: Alberto Raggi

Copyright (c) 2014 Brenna Bath et al. This is an open access article distributed under the Creative Commons Attribution License, which permits unrestricted use, distribution, and reproduction in any medium, provided the original work is properly cited.

\begin{abstract}
Chronic back disorders (CBD) are a significant public health concern. Profiling Canadians with CBD and the associated biopsychosocial factors at a national population level is important to understand the burden of this condition and how clinicians, health systems, and related policies might address this potentially growing problem. We performed a secondary analysis of the 2009 and 2010 Canadian Community Health Surveys to calculate prevalence and to better understand the differences between people with and without CBD. An estimated 20.2\% of the adult Canadian population reports having back problems lasting for 6 months or more. Among people with CBD, there was significantly greater likelihood of living in a more rural or remote location, being Aboriginal, being a former or current smoker, being overweight, having other chronic health conditions, having greater activity limitations, having higher levels of stress, and having lower perceived mental health. People who were single/never married or had an ethnicity other than Caucasian or Aboriginal were less likely to report having CBD. These results contribute to a growing body of research in the area that may assist with strategic prioritization and tailoring of health promotion efforts and health services for people with CBD, particularly among vulnerable groups.
\end{abstract}

\section{Introduction}

Musculoskeletal disorders comprise a surprisingly large share of the nonfatal disease burden around the world. International data suggest that chronic pain states, such as chronic back disorders (CBD), present a burden at least as great as, or perhaps even greater than, conditions that are conventionally prioritised as public health concerns [1]. In a recent review of the global burden of 290 diseases and conditions, low back pain was found to be the leading cause of years lived with disability [2]. Musculoskeletal conditions, such as low back pain, are likely to increasingly dominate the picture of disability at a population level as the demographic structure of society changes. Low back pain and related disorders have a large societal and personal impact estimated to affect $50-85 \%$ of all people at some time in life [3]. The economic consequences of back disorders represent an enormous cost for society due to direct health-care utilization costs and indirect costs such as loss of productivity and lost wages [4]. In Canada, medical expenditures with respect to back disorders are estimated between $\$ 6$ and $\$ 12$ billion annually [5]. Although clinical practice guidelines suggest that recovery from an initial onset of acute back pain is usually rapid and complete [6], more recent evidence suggests that persisting (i.e., chronic) pain and disability for up to a year or more are not uncommon [7]. 
The biopsychosocial model is proposed as a means to more completely understand, evaluate, and manage disability attributed to persisting health conditions such as CBD [8-10]. This model draws on broader understanding of biological and psychosocial influences on the development and persistence of pain and disability; it does not reject a search for important pathology but rather shifts the emphasis to other components of the problem [11]. Even though back pain may start as a physical or biological problem, people with back pain and the health-care providers working with them often view the physical symptom through a series of psychological and social filters [9]. A social model explains disability as being primarily caused by oppressive social and economic conditions. In contrast, a biomedical model has an individual focus and assumes a direct link between pain, disease, and physical pathology. The biopsychosocial approach is a compromise between a purely biomedical and a purely social model of disability and reflects the concept that disability related to $\mathrm{CBD}$ should be viewed as a problem arising from the interaction between physical/biological (e.g., age, sex, and physical exposures), psychological (i.e., cognition, affect, and behavior), and social factors (i.e., social and cultural contexts) $[8,9,12,13]$. The biopsychosocial model forms the basis of the World Health Organization's International Classification of Functioning, Disability, and Health (ICF) [14-16]. The ICF represents a comprehensive classification system that makes it possible to describe disability at a variety of biological, personal, or societal levels in the context of environmental factors that may either enhance or detract from overall health and wellness $[14,16]$. The ICF provides a framework in which tissue damage may be a relatively small component of a musculoskeletal problem and acknowledges that psychological, social, and cultural contexts contribute to health outcomes including participation in social and other life activities [17].

A variety of biopsychosocial factors, including age, social support, depression, and other comorbidities, have been linked to persisting pain and disability in people with back disorders $[13,18-20]$. In the context of CBD, psychological and social factors are thought to be just as important as (if not more important than) biomedical or physical factors $[18,19,21]$. Prior research using Canadian data has examined predictors of new-onset CBD [22], the association between CBD and depression [20], and self-reported health-care utilization among people with and without CBD [23]. However, to the best of our knowledge, investigation of both the prevalence of CBD and examination of the association of a range of biopsychosocial factors with CBD in a population-based sample of Canadian adults has yet to be done. Notably, much of the population-based back pain research internationally has focused on prevalence of back pain (using a range of case definitions) [24-26] or focused on a narrow subset of biopsychosocial factors, such as age, gender, depression, or occupational risk factors [24, 26-28]. Furthermore, there appears to be very few countrywide studies on CBD prevalence, particularly ones that consider a range of biopsychosocial factors [24]. Among 165 included studies in a systematic review of the global prevalence of low back pain, only 13 (7.9\%) examined chronic (i.e., >3-month duration) or recurrent low back pain, and among those, only 2 studies had a nationally representative sample $[20,29]$. However, neither nationally representative study examined CBD alone as the dependent variable of interest or profiled the biological, psychological, and social factors associated with CBD. Currie and colleagues focused on the relationship between CBD and depression [20]. Makela et al. investigated how a range of musculoskeletal disorders (including CBD) were associated with disability, but not the biopsychosocial factors associated with CBD [29].

Determining the prevalence of CBD and profiling its associated biological, psychological, and social factors at a national population level are important to understand the burden of this condition and how clinicians, health systems, and related policies might address this potentially growing public health problem. The aim of this study was to determine the prevalence of self-reported CBD and to profile the sociodemographics, comorbidities, perceived disability, and other health status indicators among people with CBD compared to people without $\mathrm{CBD}$ in the Canadian adult population.

\section{Materials and Methods}

2.1. Study Design and Data Source. We used data from Statistics Canada's 2009 and 2010 Canadian Community Health Surveys (CCHS). The CCHS was designed to provide a flexible survey instrument to address emerging health issues in Canada. It includes a range of content such as sociodemographics, health status, health behaviours, and many other determinants of health [30]. The CCHS is a cross-sectional study in which respondents are selected using a complex survey design with a two-phase stratified sampling plan intended to ensure adequate representation from each Canadian region.

2.2. Study Population. The CCHS targets Canadians aged 12 years and older living in private dwellings in all 10 provinces and 3 territories. The survey did not include people living on First Nations reserves or residents of institutional and some noninstitutional collectives (e.g., military bases, Canadian Armed Forces vessels, merchant and coast guard vessels, campgrounds, or parks). Approximately 130000 Canadians were selected for the 2009 or 2010 survey, sampled from and representative of approximately $98 \%$ of the Canadian population aged 12 years and older. The participation rate of this survey was $72.3 \%$ [30]. The focus of our analysis was persons aged 18 years and older $(N=113647)$. Of these adult respondents, 25545 reported having a CBD.

Ethical approval for data collection was completed by Statistics Canada (Government of Canada). Our access to this data was only through approved research data centers following a rigorous screening process and approval of the proposed research in order to use this deidentified data as well as vetting procedures to ensure confidentiality and protection of the subject. 
2.3. Survey Data and Operational Definitions. The dependent variable was presence of $\mathrm{CBD}$, using the survey question: "(Do you) have back problems, excluding fibromyalgia and arthritis?" This section of the survey is prefaced with the reminder: "Now I'd like to ask about certain chronic health conditions which (you) may have. We are interested in 'longterm conditions' which are expected to last or have already lasted for 6 months or more and that have been diagnosed by a health professional."

A range of independent variables grouped into sociodemographic, lifestyle, and health characteristics were identified based on a review of the literature, clinical relevance, and data availability within the survey. The alignment of these variables with the biopsychosocial model was a further consideration for inclusion in the study. Further details regarding the description and categorization of the variables can be found in Table 1 .

2.4. Statistical Analysis. The descriptive analysis included calculation of proportions over each of our independent variables (all categorical) for persons with and without CBD using a chi-squared test suitable for complex survey data to test whether each variable was distributed differently between those with and without CBD. Crude associations between each independent variable and CBD were further assessed using bivariate logistic regression. The strength of association was quantified with the odds ratio (OR) and $95 \%$ confidence interval (CI).

In order to control for potential confounding, a multiple logistic regression model was developed. Due to the associations between many of our ordinal independent variables, a Goodman and Kruskal gamma was calculated between each pair of independent variables to determine their degrees of association. The regression model was then fitted using purposeful selection informed by statistical significance, clinical importance, potential and observed confounding effects, and the calculated gamma values. We also considered interaction terms: sex by age and sex by Health Utility Index (HUI) pain and function index. Of the interaction terms, only sex by age was retained.

All analyses were performed using Stata 13 software with built-in survey data tools for probability weights and bootstrapping. Probability weights provided by Statistics Canada were used to account for unequal probability of selection, and bootstrap methods for robust variance estimation were employed using bootstrap weights provided by Statistics Canada in order to account for the complex survey design and to accurately estimate standard errors.

\section{Results}

Estimated CBD prevalence of $20.2 \%$ in the adult Canadian population was observed. Table 2 presents the results of our descriptive and bivariate analysis. When comparing adults with and without CBD, all of the sociodemographic, lifestyle, and health characteristics we examined were significantly different between these groups at the $P<0.05$ level. Among those with $\mathrm{CBD}$, a higher proportion were female compared

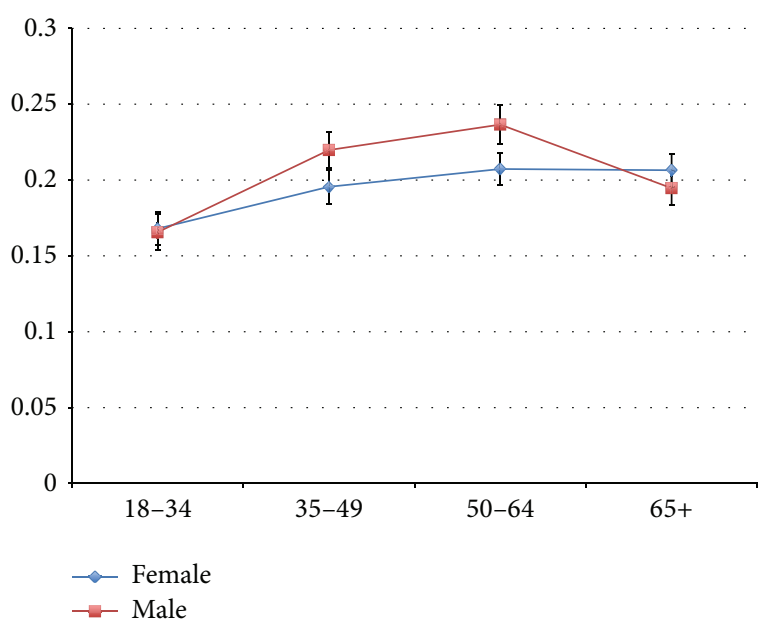

Figure 1: Predicted probabilities of CBD by age and sex.

to those who did not have CBD. Respondents with higher levels of educational attainment and higher income levels (i.e., higher income adequacy quintile) were less likely to report having CBD. People living in more rural and remote regions (i.e., moderate, weak, or no metropolitan influence zones (MIZ)) were more likely than urban or strongly influenced MIZ dwellers to report having CBD. Aboriginal respondents were more likely than Caucasians to report CBD, whereas people with "other" ethnicity were less likely than Caucasians to report CBD.

The top 5 self-reported chronic comorbidities among people with CBD were arthritis, high blood pressure, migraines, asthma, and mood disorders. Respondents who reported having any of these other chronic conditions were more likely to report having CBD. Also, people reporting having 1-2 or 3 or more chronic health conditions (other than $\mathrm{CBD}$ ) were more likely to report having CBD. Lower physical activity levels and higher time spent being sedentary were associated with a greater likelihood of reporting CBD. People with CBD were more likely than those without $\mathrm{CBD}$ to report having activity limitations due to pain.

Table 3 presents our multivariate model along with the unadjusted (bivariate) logistic regression results for each variable included in the model. All variables except residence in a strongly influenced MIZ were significant in the bivariate analysis. In the adjusted model, all variables were found to be significant except sex, education (all levels), residence in strongly or moderately influenced MIZ, being obese, and physical activity. Due to an observed interaction between sex and age category, we present a graph of predicted probability of CBD over age for each sex in Figure 1.

\section{Discussion}

The aim of this study was to determine the prevalence of $\mathrm{CBD}$ and to profile a range of variables, framed by a biopsychosocial model, among people with CBD compared to people without CBD in the Canadian adult population. 
TABLE 1: Description of (independent) variables included in analysis.

\begin{tabular}{|c|c|}
\hline Variable & Description (if applicable) and categories \\
\hline \multicolumn{2}{|c|}{ Sociodemographic characteristics } \\
\hline Age & $\begin{array}{l}18-34 \text { yrs; } 35-49 \text { yrs; } 50-64 \text { yrs; } \geq 65 \text { yrs. Categories based on quartiles and } \\
\text { clinical relevance }\end{array}$ \\
\hline Sex & Male; female \\
\hline Education & $\begin{array}{l}\text { Less than secondary; secondary graduation; some postsecondary; } \\
\text { postsecondary graduation }\end{array}$ \\
\hline Income & $\begin{array}{l}\text { A StatsCan-derived variable addressing income adequacy. Quintile of adjusted } \\
\text { ratio of total household income to the low income cut-off corresponding to } \\
\text { household and community size. This variable was unavailable for some } \\
\text { respondents, for example, in cases where the person most knowledgeable } \\
\text { about the household could not be identified }(N=92,669)\end{array}$ \\
\hline Residence & $\begin{array}{l}\text { A StatsCan-derived variable. "Urban" residence includes communities with } \\
\text { populations } \geq 10,000 \text { people. "Rural" communities are disaggregated into } \\
\text { subgroups or metropolitan influenced zones (MIZ) based on the size of } \\
\text { commuting flows to any larger urban center [31] }\end{array}$ \\
\hline Ethnicity & Caucasian; Aboriginal (i.e., North American Indian, Métis, or Inuit); other \\
\hline Marital status & Single; married or common law; widowed or separated or divorced \\
\hline Body Mass Index (BMI) & $\begin{array}{l}\text { Derived from self-reported height and weight } \\
\text { Underweight and normal }\left(<25 \mathrm{~kg} / \mathrm{m}^{2}\right) \text {; overweight }\left(25-29.9 \mathrm{~kg} / \mathrm{m}^{2}\right) \text {; } \\
\text { obese }\left(\geq 30 \mathrm{~kg} / \mathrm{m}^{2}\right)[32]\end{array}$ \\
\hline \multicolumn{2}{|r|}{ Lifestyle characteristics } \\
\hline Smoking status & Never smoked; former smoker; current smoker \\
\hline Physical activity-transportation and leisure & $\begin{array}{l}\text { A StatsCan-derived variable combining leisure time and } \\
\text { transportation-physical activity based on estimated total daily energy } \\
\text { expenditure variables (kcal/kg/day): active; moderately active; inactive }\end{array}$ \\
\hline Sedentary activity duration & $\begin{array}{l}\text { A StatsCan-derived variable of total number of hours per week spent in } \\
\text { sedentary activities (excluding reading): } 0-14 \text { hours; } 15-24 \text { hours; } 25-39 \\
\text { hours; } 40 \text { or more hours. } \\
\text { This variable was only available for respondents in the provinces of } \\
\text { Newfoundland, Manitoba, and British Columbia }(N=22,380)\end{array}$ \\
\hline \multicolumn{2}{|r|}{ Health characteristics } \\
\hline Number of other comorbidities/chronic conditions & $\begin{array}{l}\text { Includes "long-term conditions" which are expected to last or have already } \\
\text { lasted for } 6 \text { months or more and that have been diagnosed by a health } \\
\text { professional. No other chronic conditions (other than CBD); } 1 \text { or } 2 \text { chronic } \\
\text { conditions (other than CBD); } 3 \text { or more chronic conditions (other than CBD) }\end{array}$ \\
\hline Type of other comorbidities & $\begin{array}{l}\text { Presence of top } 5 \text { chronic comorbidities associated with CBD: arthritis } \\
\text { (excluding fibromyalgia); high blood pressure; migraine headaches; asthma; } \\
\text { mood disorders (i.e., depression, bipolar disorder, mania, or dysthymia) }\end{array}$ \\
\hline Perceived disability & $\begin{array}{l}\text { This variable, derived from the Health Utility Index (HUI) [33], considers } \\
\text { whether pain prevents a person from performing activities of daily living. } \\
5 \text { categories: no pain or discomfort; pain prevents no activities; pain prevents a } \\
\text { few activities; pain prevents some activities; pain prevents most activities }\end{array}$ \\
\hline Depression probability & $\begin{array}{l}\text { A StatsCan-derived variable indicating the probability that the respondent } \\
\text { would have been diagnosed as having experienced a major depressive episode } \\
\text { in the past } 12 \text { months, if they had completed the long-form composite } \\
\text { international diagnostic interview (CIDI) [34]. This variable was not available } \\
\text { for respondents that completed the survey by proxy }(N=53,017)\end{array}$ \\
\hline Self-rated stress & $\begin{array}{l}\text { Ability to handle day-to-day demands: not at all/not very; a bit; quite a } \\
\text { bit/extremely* }\end{array}$ \\
\hline Self-rated mental health & $\begin{array}{l}\text { Indicating the respondent's mental health status based on his/her own } \\
\text { judgement: excellent/very good; good; fair/poor* }\end{array}$ \\
\hline
\end{tabular}


TABle 1: Continued.

\begin{tabular}{|c|c|}
\hline Variable & Description (if applicable) and categories \\
\hline Self-rated overall health & $\begin{array}{l}\text { Indicating the respondent's health status based on his/her own judgement or } \\
\text { his/her proxy: excellent/very good; good; fair/poor* }\end{array}$ \\
\hline Self-rated work stress & $\begin{array}{l}\text { Indicating level of stress encountered "most days at work": not at all/not very; } \\
\text { a bit; quite a bit/extremely.* This variable was only available for employed } \\
\text { respondents }(N=69,992)\end{array}$ \\
\hline
\end{tabular}

${ }^{*}$ Collapsing of these categories was performed to maintain equal-sized categories and consistent categorization for all variables of interest.

Profiling those with $\mathrm{CBD}$ and its associated biological, psychological, and social factors at a national population level is important to understand the burden of this condition and how clinicians, health systems, and related policies might address this potentially growing public health problem.

We found that a substantial proportion of adult Canadians reported having back problems lasting for 6 months or more. Women had higher prevalence of CBD than men overall, but the relationship depended on age. The prevalence of CBD among men in our sample followed the typical clinical pattern described in the literature, whereby prevalence is highest in middle-aged groups (e.g., 50-64 years) and tapers off with increasing age [22]. However, this pattern was not evident among women with the prevalence of CBD among women aged 65 or more being similar to that among women aged 50-64 years. Among people with CBD, there was significantly greater likelihood of living in a more rural or remote location, being Aboriginal, being a former or current smoker, being overweight, having other chronic health conditions, having increased levels of perceived pain and activity limitations, having higher levels of stress, and having lower perceived mental health. People who were single/never married or had an ethnicity other than Caucasian or Aboriginal were less likely to report having CBD.

Comparison of studies on prevalence of back disorders is challenging due to heterogeneity across research methods, case definitions, and study populations [26]. Back disorders include a large heterogeneous group of clinical and etiological entities [35]. The most common descriptor used in epidemiological studies is "low back pain" which can represent a variety of underlying clinical conditions and duration of symptoms. Given these issues, it is unsurprising that population-based estimates of low back pain prevalence vary substantially worldwide. An estimated $15 \%$ to $20 \%$ of adults experience back pain during a single year, and $50 \%$ to $80 \%$ experience at least one episode of back pain during their lifetime [3, 24]. The sex differences we found in our study are similar to those of a recent systematic review, which found that prevalence of low back pain was higher in women overall and among older women [24]. Even though other research has shown that women are more likely to develop chronic low back pain and have higher perceived disability due to back pain [36], we did not find that sex was associated with perceived activity limitations due to pain (i.e., HUI pain and function). However, a large proportion of people with CBD reported having some degree of activity limitations, with $10.0 \%$ reporting "most" activities were limited due to pain. This finding is similar to another study in which $10.5 \%$ of an adult Australian sample reported experiencing high disability due to low back pain [25]. Further to this, a Canadian study found that musculoskeletal conditions in general were the most prevalent medical condition $(46.1 \%)$ to which activity and participation limitations were attributed [37].

There are a number of environmental, personal, and lifestyle factors that could potentially influence the onset and course of back pain. An inverse relationship between social status and educational attainment with the occurrence of back pain has been well documented in prior research [26] and confirmed in our study. Similar to our findings, Zvolensky et al. found that people with CBD were more likely to smoke than those without, an association that remained significant after adjusting for a variety of sociodemographic factors and the presence of mood or anxiety disorders [38]. The relationship between CBD and being overweight or obese and physical activity levels is equivocal as yet [39, 40], a finding echoed by our results. Psychological factors such as depression have been shown to be associated with having CBD and the development of chronic back pain [20,41]. Although "depression" was not included as a variable in our final adjusted model, self-rated mental health and perceived stress were. Further to depression, there are a number of other comorbidities that we found to be associated with CBD. A systematic review of comorbidities and low back pain found a positive association between a number of other disorders (e.g., migraines/headaches, respiratory, and cardiovascular conditions); however, the nature of the relationship between these comorbidities and CBD is unclear [42]. Not only the presence of certain chronic conditions but also the number of other conditions was highly associated with having CBD. Thus, the issue of multimorbidity is likely an important consideration when examining health-care policies and services related to $\mathrm{CBD}$.

To the best of our knowledge, the higher CBD prevalence in rural and Aboriginal Canadian populations has not previously been reported; however, these findings are not surprising given the well-documented health disparities in these populations [43]. Although higher rates of arthritis are documented in Aboriginal Canadians [43, 44], no studies have focused solely on CBD. The higher prevalence of CBD among Aboriginal people and rural and remote residents calls for further investigation into whether these groups have different biopsychosocial characteristics and thus perhaps different needs in terms of health care or health promotion related to $\mathrm{CBD}$. Research examining CBD among Aboriginal people in Australia, for example, found that the condition can be profoundly disabling and that issues of sex, cultural 
TABLE 2: Sociodemographic and lifestyle characteristics of adult Canadians with and without CBD.

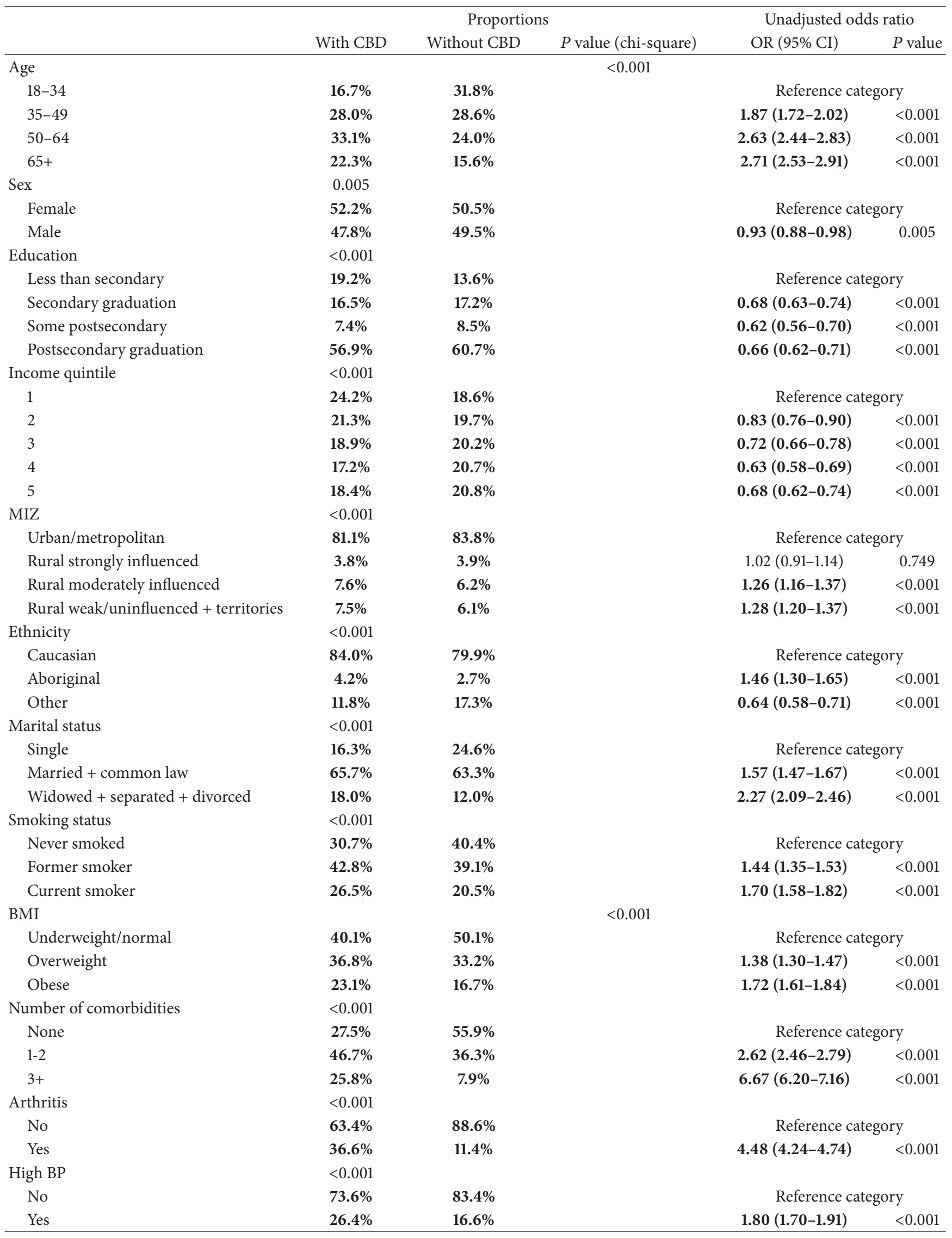


TABLe 2: Continued.

\begin{tabular}{|c|c|c|c|c|c|}
\hline & \multicolumn{3}{|c|}{ Proportions } & \multicolumn{2}{|c|}{ Unadjusted odds ratio } \\
\hline & With CBD & Without CBD & $P$ value (chi-square) & OR $(95 \% \mathrm{CI})$ & $P$ value \\
\hline Migraines & $<0.001$ & & & & \\
\hline No & $81.7 \%$ & $91.7 \%$ & & \multicolumn{2}{|c|}{ Reference category } \\
\hline Yes & $18.3 \%$ & $8.3 \%$ & & $2.47(2.30-2.66)$ & $<0.001$ \\
\hline Asthma & $<0.001$ & & & & \\
\hline No & $87.3 \%$ & $93.2 \%$ & & \multicolumn{2}{|c|}{ Reference category } \\
\hline Yes & $12.7 \%$ & $6.8 \%$ & & $2.01(1.85-2.19)$ & $<0.001$ \\
\hline Mood disorders & $<0.001$ & & & & \\
\hline No & $86.9 \%$ & $94.7 \%$ & & \multicolumn{2}{|c|}{ Reference category } \\
\hline Yes & $13.1 \%$ & $5.3 \%$ & & $2.73(2.52-2.95)$ & $<0.001$ \\
\hline Physical activity-transportation and leisure & $<0.001$ & & & & \\
\hline Active & $22.3 \%$ & $28.0 \%$ & & \multicolumn{2}{|c|}{ Reference category } \\
\hline Moderately active & $23.3 \%$ & $26.2 \%$ & & $1.11(1.04-1.21)$ & 0.008 \\
\hline Inactive & $54.3 \%$ & $45.8 \%$ & & $1.48(1.39-1.58)$ & $<0.001$ \\
\hline Sedentary activity & $<0.001$ & & & & \\
\hline 0 to 14 hours & $21.9 \%$ & $25.2 \%$ & & \multicolumn{2}{|c|}{ Reference category } \\
\hline 15 to 24 hours & $29.2 \%$ & $31.6 \%$ & & $1.06(0.91-1.25)$ & 0.433 \\
\hline 25 to 39 hours & $29.6 \%$ & $27.4 \%$ & & $1.24(1.07-1.45)$ & 0.005 \\
\hline 40 or more hours & $19.3 \%$ & $15.9 \%$ & & $1.40(1.18-1.66)$ & $<0.001$ \\
\hline Perceived disability & $<0.001$ & & & & \\
\hline No pain or discomfort & $53.5 \%$ & $88.7 \%$ & & \multicolumn{2}{|c|}{ Reference category } \\
\hline Pain prevents no activities & $9.5 \%$ & $3.8 \%$ & & $4.12(3.73-4.55)$ & $<0.001$ \\
\hline Pain prevents a few activities & $14.2 \%$ & $3.7 \%$ & & $6.40(5.84-7.01)$ & $<0.001$ \\
\hline Pain prevents some activities & $12.7 \%$ & $2.3 \%$ & & $9.03(8.17-9.98)$ & $<0.001$ \\
\hline Pain prevents most activities & $10.0 \%$ & $1.5 \%$ & & $11.32(9.99-12.82)$ & $<0.001$ \\
\hline Depression scale predicted probability & & & $<0.001$ & & \\
\hline$<0.9$ & $90.5 \%$ & $95.5 \%$ & & \multicolumn{2}{|c|}{ Reference category } \\
\hline$\geq 0.9$ & $9.5 \%$ & $4.5 \%$ & & $2.24(1.97-2.56)$ & $<0.001$ \\
\hline Self-rated stress & $<0.001$ & & & & \\
\hline Not at all/not very & $28.0 \%$ & $35.9 \%$ & & \multicolumn{2}{|c|}{ Reference category } \\
\hline A bit & $41.0 \%$ & $42.2 \%$ & & $1.25(1.18-1.32)$ & $<0.001$ \\
\hline Quite a bit/extremely & $31.1 \%$ & $21.9 \%$ & & $1.83(1.71-1.95)$ & $<0.001$ \\
\hline Self-rated mental health & $<0.001$ & & & & \\
\hline Excellent/very good & $62.2 \%$ & $76.5 \%$ & & \multicolumn{2}{|c|}{ Reference category } \\
\hline Good & $27.4 \%$ & $19.4 \%$ & & $1.74(1.64-1.85)$ & $<0.001$ \\
\hline Fair/poor & $10.3 \%$ & $4.1 \%$ & & $3.08(2.82-3.38)$ & $<0.001$ \\
\hline Self-rated overall health & $<0.001$ & & & & \\
\hline Excellent/very good & $41.1 \%$ & $64.1 \%$ & & \multicolumn{2}{|c|}{ Reference category } \\
\hline Good & $34.1 \%$ & $27.1 \%$ & & $1.96(1.85-2.08)$ & $<0.001$ \\
\hline Fair/poor & $24.8 \%$ & $8.7 \%$ & & $4.43(4.12-4.75)$ & $<0.001$ \\
\hline Self-rated work stress & $<0.001$ & & & & \\
\hline Not at all/not very & $22.8 \%$ & $29.0 \%$ & & \multicolumn{2}{|c|}{ Reference category } \\
\hline A bit & $39.2 \%$ & $42.2 \%$ & & $1.18(1.08-1.29)$ & $<0.001$ \\
\hline Quite a bit/extremely & $38.1 \%$ & $28.8 \%$ & & $1.68(1.53-1.84)$ & $<0.001$ \\
\hline
\end{tabular}

MIZ: metropolitan influenced zone; BMI: Body Mass Index; BP: blood pressure.

obligations, and emotional consequences are important considerations for health care [45].

The results of this study should be considered in light of a number of limitations. The cross-sectional design does not permit conclusions regarding the direction of the observed associations nor does it capture the clinical course and lifetime progression of CBD. However, the national population cross-sectional approach we used in this study does allow us to capture not only new-onset or incident CBD but also those people with existing and potentially longstanding CBD. 
TABLE 3: Multivariate model of adult Canadians with and without CBD.

\begin{tabular}{|c|c|c|c|c|}
\hline & \multicolumn{4}{|c|}{ Odds ratio for $\mathrm{CBD}$} \\
\hline & \multicolumn{2}{|c|}{ Unadjusted } & \multicolumn{2}{|c|}{ Adjusted } \\
\hline & OR (95\% CI) & $P$ value & OR (95\% CI) & $P$ value \\
\hline \multicolumn{5}{|l|}{ Age } \\
\hline $18-34$ & \multicolumn{2}{|c|}{ Reference category } & \multicolumn{2}{|c|}{ Reference category } \\
\hline $35-49$ & $1.87(1.73-2.01)$ & $<0.001$ & $1.25(1.12-1.4)$ & $<0.001$ \\
\hline $50-64$ & $2.63(2.45-2.82)$ & $<0.001$ & $1.36(1.21-1.53)$ & $<0.001$ \\
\hline $65+$ & $2.71(2.54-2.9)$ & $<0.001$ & $1.35(1.2-1.53)$ & $<0.001$ \\
\hline \multicolumn{5}{|l|}{ Sex } \\
\hline Female & \multicolumn{2}{|c|}{ Reference category } & \multicolumn{2}{|c|}{ Reference category } \\
\hline Male & $0.93(0.89-0.98)$ & 0.005 & $0.98(0.87-1.1)$ & 0.739 \\
\hline \multicolumn{5}{|l|}{ Age $*$ male } \\
\hline $18-34$ & & & \multicolumn{2}{|c|}{ Reference category } \\
\hline $35-49$ & & $1.22(1.04-1.42)$ & 0.012 & \\
\hline $50-64$ & & $1.25(1.06-1.48)$ & 0.009 & \\
\hline $65+$ & & $0.93(0.8-1.09)$ & 0.384 & \\
\hline \multicolumn{5}{|l|}{ Education } \\
\hline Less than secondary & \multicolumn{2}{|c|}{ Reference category } & \multicolumn{2}{|c|}{ Reference category } \\
\hline Secondary graduation & $0.68(0.63-0.74)$ & $<0.001$ & $0.99(0.89-1.09)$ & 0.803 \\
\hline Some postsecondary & $0.62(0.56-0.69)$ & $<0.001$ & $0.93(0.82-1.06)$ & 0.267 \\
\hline Postsecondary graduation & $0.66(0.62-0.71)$ & $<0.001$ & $1.01(0.93-1.09)$ & 0.819 \\
\hline \multicolumn{5}{|l|}{ MIZ } \\
\hline Urban/metropolitan & \multicolumn{2}{|c|}{ Reference category } & \multicolumn{2}{|c|}{ Reference category } \\
\hline Rural strongly influenced & $1.02(0.91-1.15)$ & 0.749 & $0.95(0.83-1.08)$ & 0.446 \\
\hline Rural moderately influenced & $1.26(1.17-1.36)$ & $<0.001$ & $1.08(0.98-1.19)$ & 0.102 \\
\hline Rural weak/uninfluenced + territories & $1.28(1.19-1.38)$ & $<0.001$ & $1.09(1-1.18)$ & 0.046 \\
\hline \multicolumn{5}{|l|}{ Ethnicity } \\
\hline Caucasian & \multicolumn{2}{|c|}{ Reference category } & \multicolumn{2}{|c|}{ Reference category } \\
\hline Aboriginal & $1.46(1.3-1.65)$ & $<0.001$ & $1.23(1.06-1.43)$ & 0.007 \\
\hline Other & $0.64(0.58-0.71)$ & $<0.001$ & $0.84(0.76-0.94)$ & 0.002 \\
\hline \multicolumn{5}{|l|}{ Marital status } \\
\hline Single & Refer & gory & Reference & \\
\hline Married + common law & $1.57(1.47-1.67)$ & $<0.001$ & $1.15(1.06-1.25)$ & 0.001 \\
\hline Widowed + separated + divorced & $2.27(2.09-2.46)$ & $<0.001$ & $1.17(1.05-1.31)$ & 0.004 \\
\hline Smoking status & & & & \\
\hline Never smoked & Refer & gory & Reference & \\
\hline Former smoker & $1.44(1.36-1.53)$ & $<0.001$ & $1.15(1.07-1.23)$ & $<0.001$ \\
\hline Current smoker & $1.7(1.58-1.81)$ & $<0.001$ & $1.39(1.29-1.51)$ & $<0.001$ \\
\hline BMI & & & & \\
\hline Underweight/normal & Refer & gory & Reference & \\
\hline Overweight & $1.38(1.31-1.47)$ & $<0.001$ & $1.11(1.04-1.19)$ & 0.001 \\
\hline Obese & $1.72(1.61-1.83)$ & $<0.001$ & $1.02(0.95-1.1)$ & 0.576 \\
\hline Number of comorbidities & & & & \\
\hline None & Refer & gory & Reference & \\
\hline $1-2$ & $2.62(2.47-2.78)$ & $<0.001$ & $1.78(1.67-1.91)$ & $<0.001$ \\
\hline $3+$ & $6.67(6.21-7.16)$ & $<0.001$ & $2.68(2.42-2.97)$ & $<0.001$ \\
\hline Physical activity-transportation + leisure & & & & \\
\hline Active & Refer & gory & Reference & \\
\hline Moderately active & $1.11(1.03-1.2)$ & 0.008 & $0.94(0.87-1.03)$ & 0.19 \\
\hline Inactive & $1.48(1.39-1.58)$ & $<0.001$ & $0.98(0.92-1.06)$ & 0.677 \\
\hline
\end{tabular}


TABLE 3: Continued.

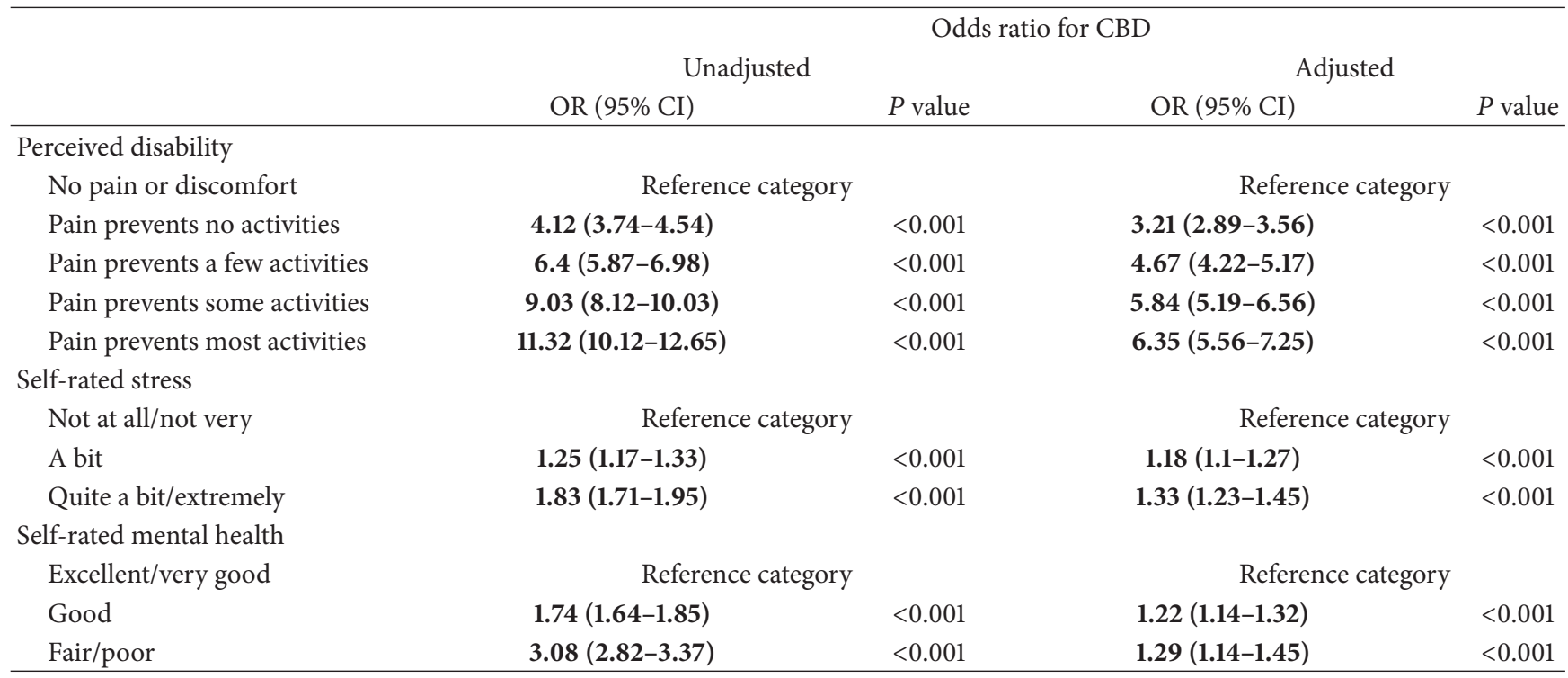

MIZ: metropolitan influenced zone; BMI: Body Mass Index; BP: blood pressure.

The classification of having CBD was derived through selfreport and may have been variably interpreted by respondents. Back disorders include a large group of clinical and etiological entities and there is no "gold standard" for clinical classification and diagnosis for many of these conditions. The International Classification of Diseases- (ICD-) 10 system does not have an adequate and distinct diagnostic code for chronic pain or $\mathrm{CBD}$ [1]. The development and international acceptance of a standard case definition for CBD would help to move the research and policy agenda for CBD forward. Although we attempted to examine a range of independent variables guided by the biopsychosocial model and identified based on a review of the literature, clinical relevance, and data availability within the survey, not all relevant variables may have been considered. Specifically, this study did not examine health-care utilization or other economic impact factors. However, many people with CBD may not necessarily seek health care for their condition or seek care during the time frame specified by the survey. In addition, CCHS data are only available for Aboriginal people living off of reserves and this analysis is limited to the categories "Aboriginal," "Caucasian," and "other" which are not homogeneous groups. Finally, the self-reported data on which this study is based may underestimate the prevalence of some behavioural risk factors, such as overweight, obesity, and smoking and overestimate the prevalence of physical activity [46].

\section{Conclusion}

This study provides insight into the magnitude and nature of CBD in Canada using a nationally representative sample. We found that a substantial proportion (20.2\%) of adult Canadians report having back problems lasting for 6 months or more. A variety of modifiable and nonmodifiable sociodemographic, health, and lifestyle factors were significantly associated with having CBD. Our results demonstrated that some biological, psychological, and sociodemographic factors are more common among Canadians with CBD than those without. Regardless of causality, understanding the unique characteristics of people with CBD can help develop more appropriate educational materials or programs (for prevention or management) and help clinicians consider potential additional health needs or potential management contraindications presented by comorbidities. Consideration of factors such as rural and remote residence, Aboriginal ethnicity, and multimorbidity may have implications for ensuring equitable access to appropriate health services and health promotion efforts. Further research should examine CBD in these potentially vulnerable groups and examine issues of health-care utilization, access, and unmet health needs.

\section{Conflict of Interests}

The authors declare that there is no conflict of interests regarding the publication of this paper.

\section{Acknowledgments}

This research was funded by Brenna Bath's University of Saskatchewan, College of Medicine, New Faculty Start-Up Fund. Catherine Trask was funded by a Canada Research Chair in Ergonomics and Musculoskeletal Health. Josh Lawson was funded by a Canadian Institutes of Health Research and Lung Association of Saskatchewan New Investigator Award. The authors would like to thank Dennis Ma, University of British Columbia, for additional statistical analysis support. 


\section{References}

[1] H. Breivik, E. Eisenberg, and T. O’Brien, “The individual and societal burden of chronic pain in Europe: the case for strategic prioritisation and action to improve knowledge and availability of appropriate care," BMC Public Health, vol. 13, article 1229, 2013.

[2] T. Vos, A. D. Flaxman, M. Naghavi et al., "Years lived with disability (YLDs) for 1160 sequelae of 289 diseases and injuries 1990-2010: a systematic analysis for the Global Burden of Disease Study 2010," The Lancet, vol. 380, no. 9859, pp. 21632196, 2012.

[3] R. C. Lawrence, D. T. Felson, C. G. Helmick et al., "Estimates of the prevalence of arthritis and other rheumatic conditions in the United States. Part II," Arthritis and Rheumatism, vol. 58, no. 1, pp. 26-35, 2008.

[4] J. N. Katz, "Lumbar disc disorders and low-back pain: socioeconomic factors and consequences," Journal of Bone and Joint Surgery A, vol. 88, supplement 2, pp. 21-24, 2006.

[5] Canada BaJD. Low Back Pain 2013, http://www.boneandjointcanada.com/?sec_id=485\&msid=3.

[6] M. Van Tulder, A. Becker, T. Bekkering et al., "Chapter 3: European guidelines for the management of acute nonspecific low back pain in primary care," European Spine Journal, vol. 15, supplement 2, pp. S169-S191, 2006.

[7] L. D. Costa, C. G. Maher, M. J. Hancock, J. H. McAuley, R. D. Herbert, and L. O. Costa, "The prognosis of acute and persistent low-back pain: a meta-analysis," Canadian Medical Association Journal, vol. 184, no. 11, pp. E613-E624, 2012.

[8] G. Waddell, "Low back pain: a twentieth century health care enigma," Spine, vol. 21, no. 24, pp. 2820-2825, 1996.

[9] G. Waddell, The Biopsychosocial Model. The Back Pain Revolution, Churchill Livingstone, Toronto, Canada, 2nd edition, 2004.

[10] A. Cieza, G. Stucki, M. Weigl et al., "ICF Core Sets for low back pain," Journal of Rehabilitation Medicine, no. 44, Supplement, pp. 69-74, 2004.

[11] P. Croft, G. Peat, and D. van der Windt, "Primary care research and musculoskeletal medicine," Primary Health Care Research \& Development, vol. 11, pp. 4-16, 2010.

[12] G. L. Engel, "The need for a new medical model: a challenge for biomedicine," Science, vol. 196, no. 4286, pp. 129-136, 1977.

[13] R. Chou and P. Shekelle, "Will this patient develop persistent disabling low back pain?" Journal of the American Medical Association, vol. 303, no. 13, pp. 1295-1302, 2010.

[14] M. Cerniauskaite, R. Quintas, C. Boldt et al., "Systematic literature review on ICF from 2001 to 2009: its use, implementation and operationalisation," Disability and Rehabilitation, vol. 33, no. 4, pp. 281-309, 2011.

[15] Who, International Classification of Functioning, Disability and Health (ICF), World Health Organization, Geneva, Switzerland, 2001.

[16] J. Jelsma, "Use of the international classification of functioning, disability and health: a literature survey," Journal of Rehabilitation Medicine, vol. 41, no. 1, pp. 1-12, 2009.

[17] G. Stucki, A. Boonen, P. Tugwell, A. Cieza, and M. Boers, "The World Health Organisation International Classification of Functioning, Disability and Health: a conceptual model and interface for the OMERACT process," Journal of Rheumatology, vol. 34, no. 3, pp. 600-606, 2007.

[18] S. J. Linton, "A review of psychological risk factors in back and neck pain," Spine, vol. 25, no. 9, pp. 1148-1156, 2000.
[19] D. I. Rubin, "Epidemiology and risk factors for spine pain," Neurologic Clinics, vol. 25, no. 2, pp. 353-371, 2007.

[20] S. R. Currie and J. Wang, "Chronic back pain and major depression in the general Canadian population," Pain, vol. 107, no. 1-2, pp. 54-60, 2004.

[21] T. Wessels, M. Van Tulder, T. Sigl, T. Ewert, H. Limm, and G. Stucki, "What predicts outcome in non-operative treatments of chronic low back pain? A systematic review," European Spine Journal, vol. 15, no. 11, pp. 1633-1644, 2006.

[22] J. A. Kopec, E. C. Sayre, and J. M. Esdaile, "Predictors of back pain in a general population cohort," Spine, vol. 29, no. 1, pp. 70-77, 2004.

[23] K.-L. Lim, P. Jacobs, and S. Klarenbach, "A population-based analysis of healthcare utilization of persons with back disorders: results from the Canadian Community Health Survey 20002001," Spine, vol. 31, no. 2, pp. 212-218, 2006.

[24] D. Hoy, C. Bain, G. Williams et al., "A systematic review of the global prevalence of low back pain," Arthritis \& Rheumatism, vol. 64, no. 6, pp. 2028-2037, 2012.

[25] B. F. Walker, R. Muller, and W. D. Grant, "Low back pain in australian adults. Prevalence and associated disability," Journal of Manipulative and Physiological Therapeutics, vol. 27, no. 4, pp. 238-244, 2004.

[26] D. Hoy, P. Brooks, F. Blyth, and R. Buchbinder, “The Epidemiology of low back pain," Best Practice and Research: Clinical Rheumatology, vol. 24, no. 6, pp. 769-781, 2010.

[27] K. Demyttenaere, R. Bruffaerts, S. Lee et al., "Mental disorders among persons with chronic back or neck pain: results from the world mental health surveys," Pain, vol. 129, no. 3, pp. 332-342, 2007.

[28] K. Walker-Bone and K. T. Palmer, "Musculoskeletal disorders in farmers and farm workers," Occupational Medicine, vol. 52, no. 8, pp. 441-450, 2002.

[29] M. Makela, M. Heliovaara, K. Sievers, P. Knekt, J. Maatela, and A. Aromaa, "Musculoskeletal disorders as determinants of disability in Finns aged 30 years or more," Journal of Clinical Epidemiology, vol. 46, no. 6, pp. 549-559, 1993.

[30] StatisticsCanada, Canadian Community Health Survey (CCHS) - Annual component: user guide 2010 and 2009-2010 Microdata files, 2011, http://www23.statcan.gc.ca/imdb-bmdi/ pub/document/3226_D7_T9_V8-eng.htm.

[31] V. du Plessis, R. Beshiri, R. Bollman, and H. Clemenson, Definitions of "Rural" Agricultural and Rural Working Paper Series No. 61, Statistics Canadam Agriculture Division, Ottawa, Canada, 2002.

[32] American College of Sports Medicine, ACSM's Guidelines for Exercise Testing and Prescription, Williams \& Wilkins, Baltimore, Md, USA, 5th edition, 1995.

[33] D. Feeny, W. Furlong, G. W. Torrance et al., "Multiattribute and single-attribute utility functions for the Health Utilities Index Mark 3 system," Medical Care, vol. 40, no. 2, pp. 113-128, 2002.

[34] R. C. Kessler and B. Üstün, "The World Mental Health (WMH) Survey Initiative version of the World Health Organization (WHO) Composite International Diagnostic Interview (CIDI)," International Journal of Methods in Psychiatric Research, vol. 13, no. 2, pp. 93-117, 2004.

[35] A. D. Woolf and B. Pfleger, "Burden of major musculoskeletal conditions," Bulletin of the World Health Organization, vol. 81, no. 9, pp. 646-656, 2003.

[36] E. Thomas, A. J. Silman, P. R. Croft, A. C. Papageorgiou, M. I. V. Jayson, and G. J. Macfarlane, "Predicting who develops 
chronic low back pain in primary care: a prospective study," British Medical Journal, vol. 318, no. 7199, pp. 1662-1667, 1999.

[37] D. Goodridge, J. Lawson, D. Marciniuk, and D. Rennie, "A population-based profile of adult Canadians living with participation and activity limitations," Canadian Medical Association Journal, vol. 183, no. 13, pp. E1017-E1024, 2011.

[38] M. J. Zvolensky, K. A. McMillan, A. Gonzalez, and G. J. G. Asmundson, "Chronic musculoskeletal pain and cigarette smoking among a representative sample of Canadian adolescents and adults," Addictive Behaviors, vol. 35, no. 11, pp. 10081012, 2010.

[39] H. Heneweer, F. Staes, G. Aufdemkampe, M. Van Rijn, and L. Vanhees, "Physical activity and low back pain: a systematic review of recent literature," European Spine Journal, vol. 20, no. 6, pp. 826-845, 2011.

[40] J.-F. Chenot, A. Becker, C. Leonhardt et al., "Sex differences in presentation, course, and management of low back pain in primary care," Clinical Journal of Pain, vol. 24, no. 7, pp. 578584, 2008.

[41] L. J. Carroll, J. D. Cassidy, and P. Côté, "Depression as a risk factor for onset of an episode of troublesome neck and low back pain," Pain, vol. 107, no. 1-2, pp. 134-139, 2004.

[42] L. Hestbaek, C. Leboeuf-Yde, and C. Manniche, "Is low back pain part of a general health pattern or is it a separate and distinctive entity? A critical literature review of comorbidity with low back pain," Journal of Manipulative and Physiological Therapeutics, vol. 26, no. 4, pp. 243-252, 2003.

[43] C. Loppie Redding and F. Wien, Health Inequalities and Social Determinants of Aboriginal Peoples' Health, National Collaborating Centre for Aboriginal Health, University of Northern British Columbia, Prince George, BC, Canada, 2009.

[44] C. Ng, S. Chatwood, and T. K. Young, "Arthritis in the Canadian Aboriginal population: North-south differences in prevalence and correlates," Chronic Diseases in Canada, vol. 31, no. 1, pp. 22-26, 2010.

[45] I. B. Lin, P. B. O’Sullivan, J. A. Coffin, D. B. Mak, S. Toussaint, and L. M. Straker, "Disabling chronic low back pain as an iatrogenic disorder: a qualitative study in Aboriginal Australians," BMJ Open, vol. 3, no. 4, 2013.

[46] S. Connor Gorber, M. Shields, M. S. Tremblay, and I. McDowell, "The feasibility of establishing correction factors to adjust selfreported estimates of obesity," Health Reports (Statistics Canada, Catalogue 82-003-XPE), vol. 19, no. 3, pp. 71-82, 2008. 


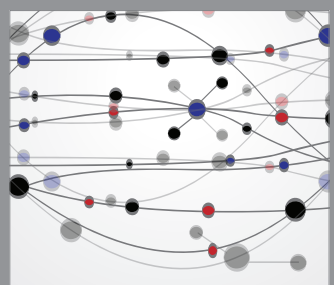

The Scientific World Journal
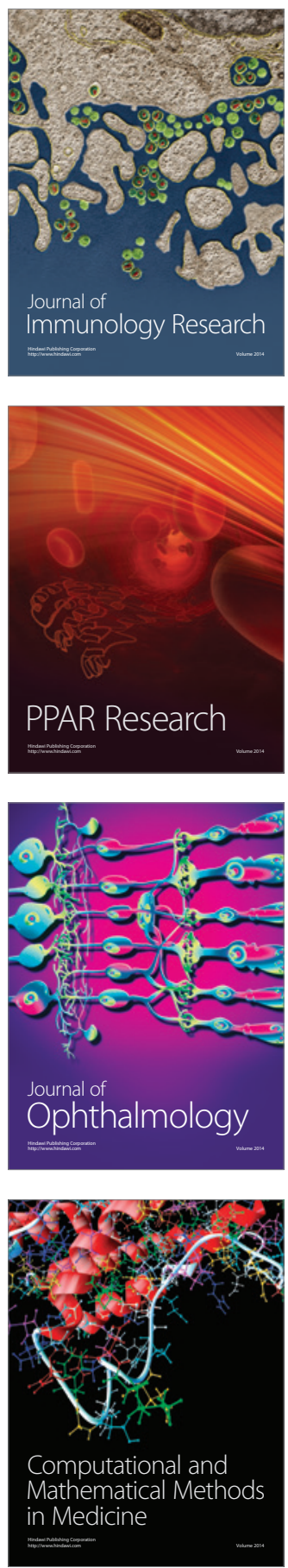

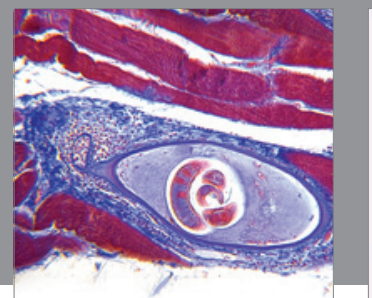

Gastroenterology

Research and Practice
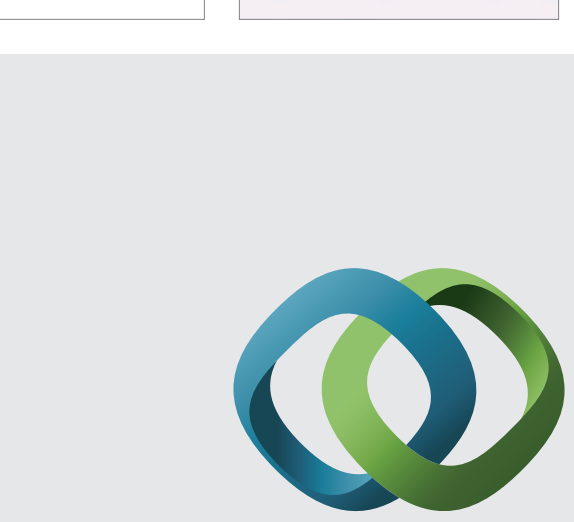

\section{Hindawi}

Submit your manuscripts at

http://www.hindawi.com
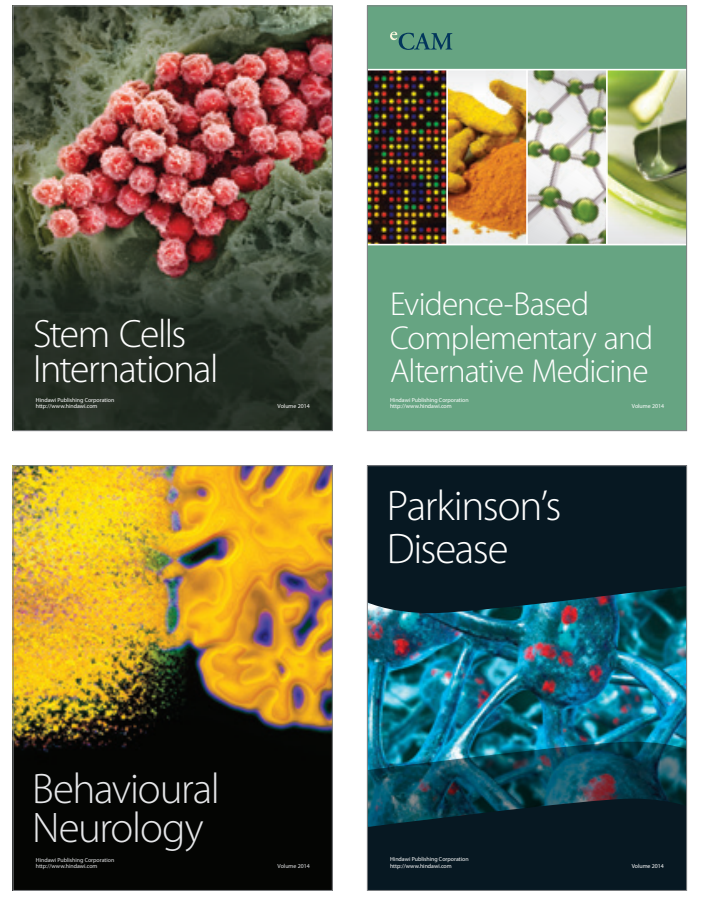
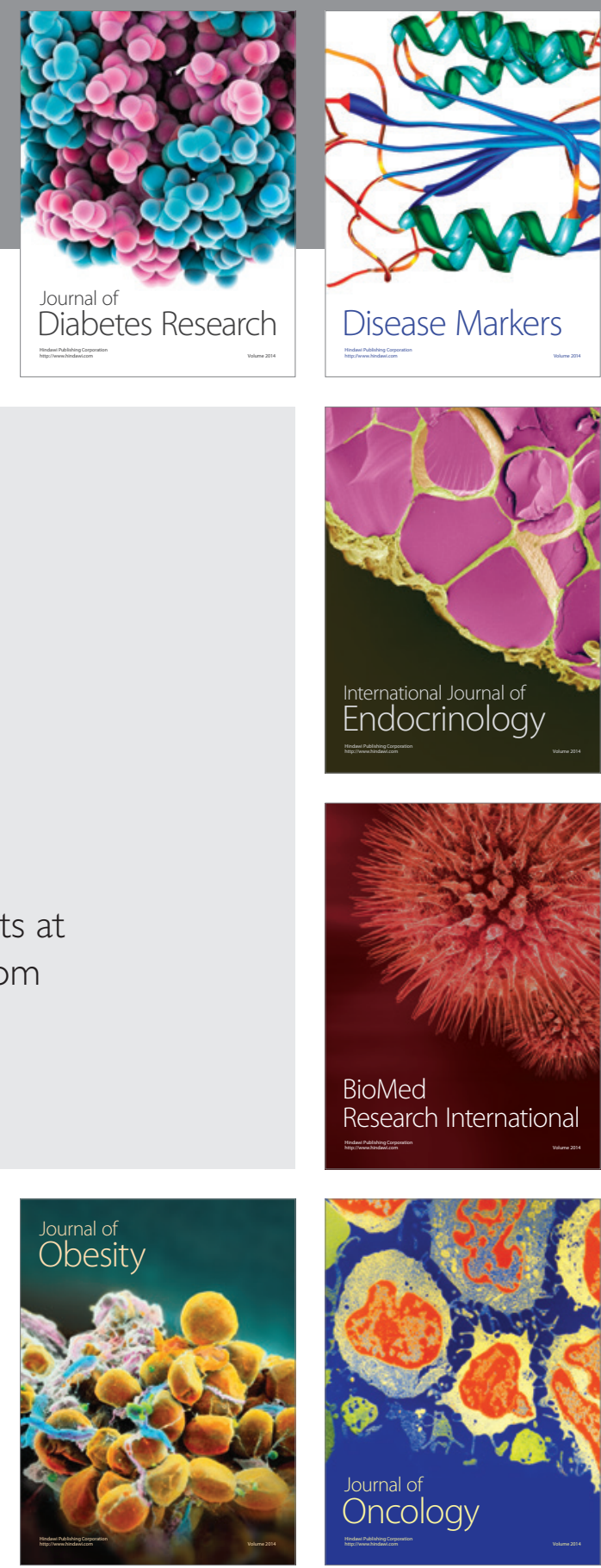

Disease Markers
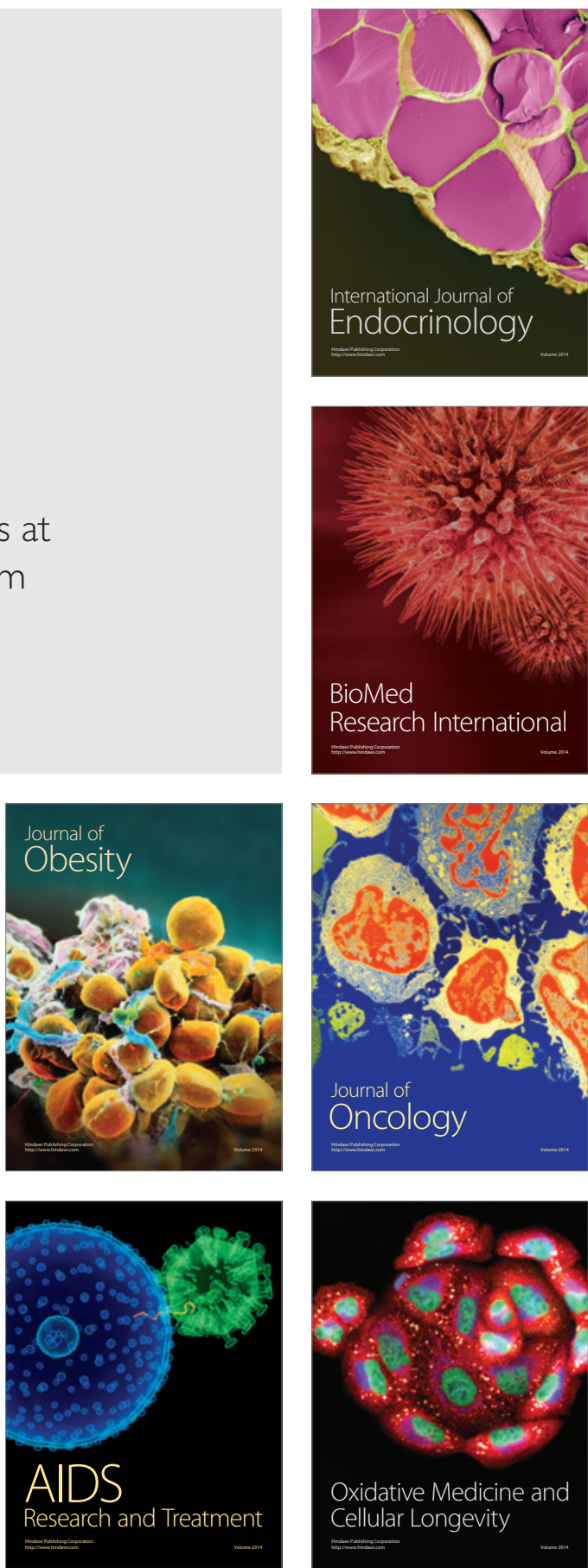